\title{
Ezenwa-Ohaeto. -- Chinua Achebe. A Biography. Oxford, James Currey/Bloomington-Indianapolis, Indiana University Press, 1997, 326 p.
}

Jean Sévry

\section{(2) OpenEdition}

Journals

Édition électronique

URL : http://journals.openedition.org/etudesafricaines/21

DOI : 10.4000/etudesafricaines.21

ISSN : $1777-5353$

Éditeur

Éditions de l'EHESS

Édition imprimée

Date de publication : 1 janvier 2000

ISBN : 978-2-7132-1346-5

ISSN : 0008-0055

Référence électronique

Jean Sévry, «Ezenwa-Ohaeto. -- Chinua Achebe. A Biography. Oxford, James Currey/BloomingtonIndianapolis, Indiana University Press, 1997, 326 p. », Cahiers d'études africaines [En ligne], 157 | 2000, mis en ligne le 24 avril 2003, consulté le 22 septembre 2020. URL : http://journals.openedition.org/ etudesafricaines/21 ; DOI : https://doi.org/10.4000/etudesafricaines.21

Ce document a été généré automatiquement le 22 septembre 2020.

(c) Cahiers d'Études africaines 


\title{
Ezenwa-Ohaeto. -- Chinua Achebe. A Biography. Oxford, James Currey/ Bloomington-Indianapolis, Indiana University Press, 1997, 326 p.
}

\author{
Jean Sévry
}

La gloire d'Achebe s'étend maintenant bien au-delà des frontières du continent africain. Si un chef-d'oeuvre comme Le Monde s'effondre a connu dès 1969 un tirage de 400000 exemplaires, ce chiffre va dépasser les trois millions en 1987, et il aura été alors traduit en pas moins de quarante-cinq langues. C'est ce que nous rapporte l'auteur de cette énorme biographie. Il nous retrace au jour le jour la vie à la fois trépidante et paisible de ce remarquable auteur qui a joué un rôle de tout premier plan dans la diffusion des littératures africaines. Achebe a été également un prodigieux découvreur de talents, ainsi au travers d'un périodique comme Obike, dont il a été le rédacteur en chef à partir de 1972. C'est ainsi qu'il prendra entièrement entre ses mains la destinée littéraire d'une romancière comme Flora Nwapa (pp. 93-94) : que serait devenue son oeuvre sans la diligence d'Achebe ? Ezenwa-Ohaeto nous décrit fort bien les déchirements de conscience que connut Achebe lors de la guerre du Biafra, en tant qu'Ibo. Il y perdit sa maison, de précieux documents, assista à quelques massacres et à la mort tragique de Christopher Okigbo (pp. 155, 223). Il joua alors le rôle d'un ambassadeur itinérant afin de pouvoir plaider sa cause. Soyinka était déjà en prison. Tout au long de sa vie, les séjours à l'étranger et les rencontres sont allés en se multipliant (Ulli Beier, James Baldwin, etc.) : l'homme n'était pas avare de sa personne. Et le malheur qui le bloqua sur la fin de sa vie dans une chaise roulante ne lui retira pas une parcelle de sa grande dignité.

Ce livre fourmille de détails, dont certains sont précieux, soit qu'ils viennent confirmer quelques hypothèses déjà émises par la critique internationale, soit parce qu'ils jettent un jour nouveau sur tel ou tel aspect de l'oeuvre. C'est ainsi que nous trouvons la confirmation d'une enfance au village qui fut de quelque importance puisque c'est dans cette mémoire qu'Achebe viendra souvent se ressourcer. On découvre par la même 
occasion (ce qui est plus intéressant) tout le chemin qu'il a dû parcourir pour se défaire de l'influence pesante des littératures coloniales. Au Collège de Umuahia, il lisait déjà Dickens, Swift et bien d'autres, ainsi Parrinder dont il suivra les cours plus tard et qui renforcera l'intérêt porté aux systèmes religieux (pp. 42-44). Mais il était également, ce qui me semble normal pour un homme de son temps et de son âge, un fervent lecteur de littérature coloniale populaire : Rider Haggard, John Buchan, ou Edgar Wallace, ce qui a pu l'entraîner plus loin qu'il ne l'aurait souhaité (je traduis) : « Au début, je ne me percevais pas comme un Africain. Je prenais parti avec les hommes blancs contre les sauvages. En d'autres termes, je traversai les premières années de ma scolarité avec l'idée que je faisais partie de ce monde du Blanc, fait d'aventures à vous arracher les cheveux, et d'escapades miraculeuses. Ce Blanc était bon, il était raisonnable, intelligent et courageux. Les sauvages qui se dressaient contre lui étaient sinistres, stupides, ou, au mieux, fourbes. Je ne pouvais pas les blairer » (p. 27). Il lui faudra donc un certain temps pour se détacher de cette aliénation coloniale, il prendra sa revanche avec Joyce Cary ou Joseph Conrad qu'il se gardera bien de ménager. Au détour des pages, on découvre également les aspects très attachants de sa personnalité, sa tolérance et son refus des illusions. Ainsi lorsqu'il se rend en Rhodésie en 1961. Dans un autocar, à ses propres dépens, il découvre le poids de la ségrégation et du racisme ambiant en prenant place à côté du chauffeur d'un car. On est au bord d'un incident. Et voici la réaction d'Achebe (p. 83) : « Les passagers noirs qui étaient à l'arrière se précipitèrent pour m'attendre à la sortie du bus afin de m'acclamer et de prononcer mes louanges. Mais pour ma part, je n'éprouvai aucun enthousiasme. Une immense tristesse s'empara de moi. » De la même façon, lorsque vers la fin de sa brillante carrière, de jeunes loups viennent lui reprocher de trop envahir la scène, il sait garder toute la distance nécessaire sans faire pour autant preuve de suffisance. On trouvera également dans cette énorme étude un débat assez intéressant sur certaines querelles qui ont entouré les sources écrites de La flèche de Dieu. Il semblerait qu'Achebe soit allé puiser des informations dans une étude de C. Nnolim, The History of Umuchu (pp. 199-200). Mais la lecture de ce livre devient assez rapidement lassante. C'est que son auteur ne nous épargne pas le moindre petit fait ; aucun détail ne lui échappe. Il ne cesse de consulter les avis de la critique, de la presse, des témoins pour pouvoir tisser une trame que pour ma part je finis par trouver étouffante. Ainsi, à propos de querelles fort mesquines dont les universitaires sont malheureusement si friands (pp. 238-239) ou encore, à propos de la parution de l'essai important intitulé The Trouble with Nigeria dont notre auteur se contente de résumer les thèses le plus platement du monde. On se demande, au fil des pages, où ont bien pu passer les réflexions d'Ezenwa-Ohaeto. S'agit-il, en la circonstance, d'une modestie excessive ? Mais en ce cas, la biographie tourne court et se réduit à un amas de faits plus ou moins organisés. On ne trouvera pas la moindre réflexion sur l'ensemble de l'oeuvre, sur ses aspects proprement génétiques (ce qui représente un risque à prendre pour tout biographe). À force de ne pas vouloir faire de vagues, on ne bouge plus, on stagne dans une sorte d'immobilité respectueuse ; à force de vouloir rester dans la prudence et la neutralité, et de vouloir renier toute visée proprement littéraire ou esthétique, l'ouvrage sombre dans un certain ennui, dans la contemplation d'un monument. Achebe méritait certainement mieux qu'une pesante compilation. On a quelque peine, à l'occasion, à retrouver toute la chaleur humaine qu'il pouvait dégager autour de lui, ses enthousiasmes, ou ses colères. Dès le départ, il a bien fait comprendre à « son " biographe qu'il entendait ne pas participer à cette opération (p. 8). Ce livre fourmille de 
renseignements précieux, mais il manque étrangement d'ambitions littéraires. On aurait pu s'attendre, entre autres, à ce que son auteur s'interroge quelque peu sur ce qu'est une biographie (beaucoup de critiques et d'écrivains ne cessent de se poser cette question), ou sur son utilité. 